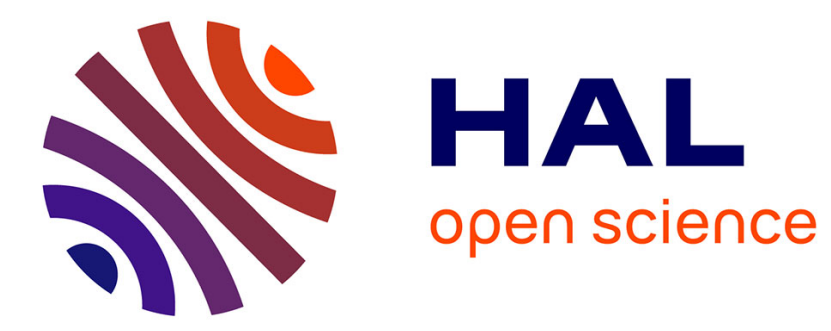

\title{
Study of phase transitions in piezoelectric polyvinylidene fluoride
}

\author{
M. Latour, H. Abo Dorra
}

\section{To cite this version:}

M. Latour, H. Abo Dorra. Study of phase transitions in piezoelectric polyvinylidene fluoride. Revue de Physique Appliquée, 1985, 20 (3), pp.137-142. 10.1051/rphysap:01985002003013700 . jpa-00245315

\section{HAL Id: jpa-00245315 https://hal.science/jpa-00245315}

Submitted on 1 Jan 1985

HAL is a multi-disciplinary open access archive for the deposit and dissemination of scientific research documents, whether they are published or not. The documents may come from teaching and research institutions in France or abroad, or from public or private research centers.
L'archive ouverte pluridisciplinaire HAL, est destinée au dépôt et à la diffusion de documents scientifiques de niveau recherche, publiés ou non, émanant des établissements d'enseignement et de recherche français ou étrangers, des laboratoires publics ou privés. 
Classification

Physics Abstracts

$61.40-77.60-07.65 \mathrm{G}-33.20 \mathrm{E}$

\title{
Study of phase transitions in piezoelectric polyvinylidene fluoride
}

\author{
M. Latour and H. Abo Dorra \\ Laboratoire de Physique Moléculaire et Cristalline (LA 233), \\ Université des Sciences et Techniques du Languedoc, 34060 Montpellier Cedex, France
}

(Reçu le 29 mai 1984, révisé les 3 octobre et 6 décembre, accepté le 13 décembre 1984)

\begin{abstract}
Résumé. - Par une étude spectroscopique en infrarouge on montre que pour le poly(fluorure de vinylidène) la transition de phase d'une structure non polaire vers une structure polaire s'effectue diversement selon l'origine des résines utilisées. Les échantillons présentant ici (avant polarisation) une structure mélange des phases polaires et non polaires (typiquement $\beta$ et $\alpha$ ), polarisés dans les mêmes conditions, montrent différents types d'évolution structurale.
\end{abstract}

\begin{abstract}
It is shown by infrared measurements in poly(vinylidene fluoride) that the phase transition from a nonpolar to a polar structure appears to be different for samples of different origin. These samples present an initial structure with mixed polar and nonpolar crystalline phases (typically $\beta$ and $\alpha$ ); polarized under identical conditions, they show different types of structural evolution.
\end{abstract}

\section{Introduction.}

Several works have been devoted to the phase transitions in polyvinylidene fluoride (PVDF) under electrical or mechanical stress [1-5]. Commonly most authors agree on an evolution from a nonpolar phase $\alpha$ to a polar phase $\left(\alpha_{\mathrm{p}}\right.$, or $\left.\beta\right)$, coming from a dipolar rearrangement in the crystal part of the polymer. We show that this evolution appears different for samples of different origin.

The purpose of this paper is to compare the phase transitions in PVDF due to the polarization of different samples provided by four industrial groups : Solvay (Belgium), Kureha Chemical Ind. (Japan), Pennwalt Chemicals Co. (USA) and Rhône-Poulenc (France). The results presented in this study are mostly carried out using infrared Fourier transform techniques.

\section{Materials and samples.}

The spectra in the mid and far infrared regions are recorded on a Fourier transform spectrometer Bruker type IFS $113 \mathrm{~V}$ in polarized light. Dynamic piezoelectric measurements are performed at a frequency of $25 \mathrm{~Hz}$ on an apparatus built in the laboratory [6]. All samples are polarized in the same conditions under electrostatic fields of $1 \mathrm{MV} / \mathrm{cm}$. All films are gold metallized on both sides before polarization.
We have used films with thickness varying from 8 to $10 \mu$ for the mid infrared regions $\left(400\right.$ to $\left.4000 \mathrm{~cm}^{-1}\right)$, and 75 to $100 \mu$ for the far infrared regions (50 to $500 \mathrm{~cm}^{-1}$ ). Before polarization, all samples present a proportion of crystalline and amorphous phase of about $50 \%$. In the crystalline phase, these samples present a structure of mixed $\alpha$ and $\beta$ forms. Table I summarizes some characteristics of the samples before their polarization. Typically, we have used two kinds of resin, one obtained by suspension (Kureha, Solvay, Rhône-Poulenc) and the other by emulsion (Pennwalt). Generally [7], the distribution of the molecular weights is broader for the samples obtained by emulsion than for the suspension grade.

2.1 Films from Solvay. - The previous reference to this film, Solef XION, is now Solef 1010 FEF. The resin of this polymer (suspension grade) presents a density of $1.788 \mathrm{~g} / \mathrm{cm}^{-3}$ with an average molecular weight : $\bar{M}_{\mathrm{n}}=171,000$ [7]. The dispersion of the mass is very low and remains very close to the average value $\bar{M}_{\mathrm{w}}=351,000$; and $\bar{M}_{\mathrm{w}} / \bar{M}_{\mathrm{n}}=2.05$. In this work, this resin presents the lowest dispersion of the molecular weights. The melting point is 176 to $178^{\circ} \mathrm{C}$.

If we consider the stereoregularity of the molecular chain, Nix et al. [7] show that the Solef 1010 FEF will present a quite regular structure. The perfect configuration is present at $90.4 \%$, the tail to tail 
Table I. - Characteristics of polyvinylidene fluoride samples.

\begin{tabular}{|c|c|c|c|c|c|c|c|c|c|}
\hline \multicolumn{10}{|c|}{ Characteristics of PVDF samples } \\
\hline Origin & Grade & Stretch & $\% \beta$ & $\begin{array}{l}\text { Density } \\
\mathrm{g} / \mathrm{cm}^{3}\end{array}$ & $\begin{array}{l}\text { Molecular } \\
\text { weight }\end{array}$ & $\begin{array}{c}\text { Fusion } \\
T{ }^{\circ} \mathrm{C}\end{array}$ & $\begin{array}{c}\varepsilon \\
(3 \mathrm{~Hz})\end{array}$ & \begin{tabular}{|l|} 
Defects \\
$\%\left(^{*}\right)$
\end{tabular} & Stereoregularity \\
\hline $\begin{array}{l}\text { Solef } \\
\text { XION = 1010 FEF } \\
\text { Solvay (Belgium) }\end{array}$ & Suspension & Biaxial & 50 & 1.788 & $\begin{array}{l}\bar{M}_{\mathrm{n}}=171,000 \\
\bar{M}_{\mathrm{w}}=351,200 \\
\bar{M}_{\mathrm{w}}=2.05 \\
\overline{\bar{M}}_{\mathrm{n}}\left(^{*}\right)\end{array}$ & $176-178$ & 11 & $\begin{array}{l}\mathrm{A}=90.4 \\
\mathrm{~B}=3.3 \\
\mathrm{C}=2.9 \\
\mathrm{D}=3.4\end{array}$ & $\begin{array}{l}\mathrm{A}=\text { Perfect chain } \\
\mathrm{CF}_{2}-\mathrm{CH}_{2}-\mathrm{CF}_{2}-\mathrm{CH}_{2}\end{array}$ \\
\hline $\begin{array}{l}\text { KF } 1000 \\
\text { Kureha Chemical } \\
\text { Ind. (Japan) }\end{array}$ & Suspension & $\begin{array}{l}\text { Biaxial } \\
\text { Capacitor } \\
\text { grade }\end{array}$ & 23 & 1.780 & $\bar{M}_{\mathrm{n}}=170,000$ & $174-176$ & 12.8 & $C=8-10$ & $\frac{\mathrm{B}}{\mathrm{C}}=\frac{\text { Tail to tail }}{\mathrm{H}_{2}-\mathrm{CH}_{2}-\mathrm{CF}_{2}-\mathrm{CH}_{2}}$ \\
\hline $\begin{array}{l}\text { Kynar } 200(\mathrm{KCF}) \\
\text { Pennwalt Chemicals } \\
\text { Co. (USA) }\end{array}$ & Emulsion & Monoax. & 9 & 1.760 & $\begin{array}{l}\bar{M}_{\mathrm{n}}=171,000 \\
\bar{M}_{\mathrm{w}}=764,200 \\
\bar{M}_{\mathrm{w}}=4.47\end{array}$ & $161-165$ & 11 & $\begin{array}{l}\mathrm{A}=82.8 \\
\mathrm{~B}=6.1 \\
\mathrm{C}=5.6 \\
\mathrm{D}=5.5\end{array}$ & $\begin{array}{l}\underline{\mathrm{C}}=\underline{\text { Head to head }} \\
\mathrm{CF}_{2}-\mathrm{CH}_{2}-\mathrm{CF}_{2}-\mathrm{CF}_{2} \\
\underline{\mathrm{D}}=\underline{\mathrm{T} \text { to } \mathrm{T} \text { and } \mathrm{H} \text { to } \mathrm{H}}\end{array}$ \\
\hline $\begin{array}{l}\text { Rhône-Poulenc } \\
\text { (France) }\end{array}$ & Suspension & Monoax. & 23 & 1.700 & $\bar{M}_{\mathrm{n}}=171,000$ & $165-168$ & 11 & $\mathrm{C}=11$ & $\mathrm{CH}_{2}-\mathrm{CH}_{2}-\mathrm{CF}_{2}-\mathrm{CF}_{2}$ \\
\hline
\end{tabular}

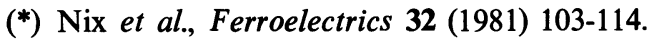

defects $3.3 \%$, the head to head defects $2.9 \%$, and the tail to tail followed by head to head $3.4 \%$. In this work, the forms $\alpha$ and $\beta$ present in the crystalline phase are equally represented : $50 \%$. The dielectric constant measured at $3 \mathrm{~Hz}$ is 11 .

2.2 Films From Kureha Chemical IND. - The reference of this film : KF 1000 is the bioriented capacitor grade. The monomer is polymerized in suspension, the melting point is 174 to $176^{\circ} \mathrm{C}$, and the density is $1.780 \mathrm{~g} / \mathrm{cm}^{3}$. The molecular weight is about 170,000 . The proportion of $\beta$ configuration in the crystalline phase is $23 \%$. The dielectric constant at $3 \mathrm{~Hz}$ is 12.3 ; defects of $\mathrm{C}$ type (head to head) are present at $8 \%$ [7]. It is to be noted that this sample has been provided by Kureha in 1974, this could explain the rather low piezoelectric activity of the sample (specially for the $d_{32}$ ).

2.3 Films from Pennwalt Chemicals Co. - The samples Kynar KCF 200 are calendred films, monoaxially oriented, the proportion of $\beta$ configuration in the crystalline phase is about $9 \%$. The melting point : 161 to $165^{\circ} \mathrm{C}$; the dielectric constant at $3 \mathrm{~Hz}$ is 11 ; the density : $1.760 \mathrm{~g} / \mathrm{cm}^{3}$. The average molecular weight is closed to 171,000 , as for the Solvay film, but the dispersion around this value is much broader than for the previous polymer. This film is an emulsion grade : $\bar{M}_{\mathrm{n}}=171,000, \bar{M}_{\mathrm{w}}=764,200$ and $\bar{M}_{\mathrm{w}} / \bar{M}_{\mathrm{n}}$
= 4.47. After Nix et al. [7], the perfect chains are present at $82.8 \%$, defects of stereoregularity B type ( $\mathrm{T}$ to $\mathrm{T}$ ) $6 \%$, defects of $\mathrm{C}$ type $(\mathrm{H}$ to $\mathrm{H}$ ) $5.6 \%$, and defects of $\mathrm{D}$ type ( $\mathrm{T}$ to $\mathrm{T}$ and $\mathrm{H}$ to $\mathrm{H}$ ) $5.5 \%$. The structure of this sample appears to be less perfect than those of Solvay films.

2.4 Films from Rhône-Poulenc. - The polymer (emulsion grade) is monooriented and presents in the crystalline phase a proportion of $\beta$ configuration of $23 \%$. The defects of the $\mathrm{C}$ type $(\mathrm{H}$ to $\mathrm{H})$ are present at about $11 \%$. The average molecular weight is 171,000 . The melting range is 168 to $173{ }^{\circ} \mathrm{C}$, and the dielectric constant at $3 \mathrm{~Hz}$ is 11 . These films are obtained by a chill-roll process.

It must be considered that parameters such ionic impurities metallic additives or others, present as defects or systematically incorporated during the polymerization, also affect the structure and modify the evolution of the sample configuration during the process of polarization.

\section{Results and discussion.}

Figures 1 to 4 present the spectra of the various samples in the far infrared region $\left(50\right.$ to $\left.500 \mathrm{~cm}^{-1}\right)$. The spectra were recorded in perpendicular polarized light. If we observe the spectra before polarization all absorption bands characteristic of the $\alpha$ phase, 


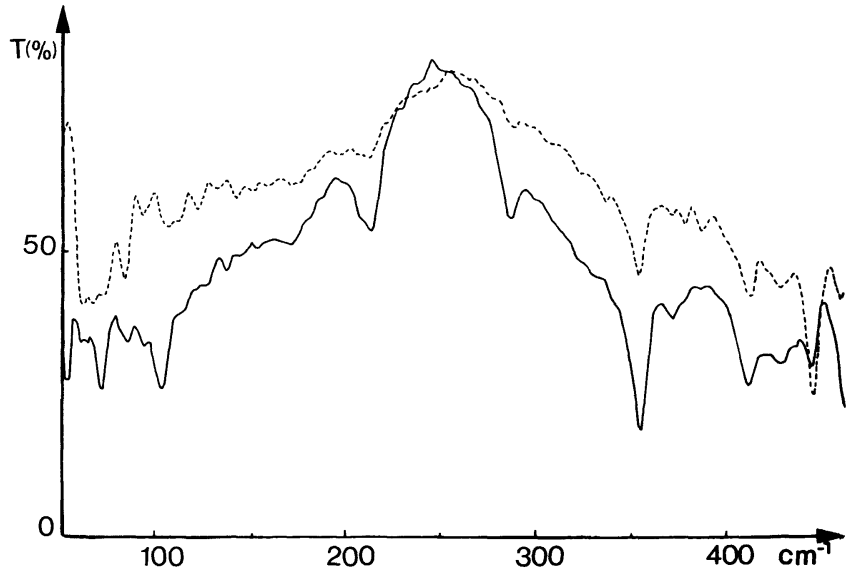

Fig. 1. - Far infrared spectra of Solef 1010 in perpendicular polarized light. Continuous line : before polarization; dashed line : after polarization.

typically $54-101-208-250-288-315-355$ and $372 \mathrm{~cm}^{-1}$ [8-9], are present, as are the bands characteristic of the $\beta$ phase, 70 and $444 \mathrm{~cm}^{-1}$ [8-9]. The assignments of all these vibrations have been extensively detailed by several authors [8-10]. Nevertheless, we observe for each sample a very characteristic profile of the spectrum, mostly in relation to the chain defects ([8] and Table I). For instance the band at $104 \mathrm{~cm}^{-1}$, which is sensitive to the order both along and between the chains $[8]\left(t\left(\mathrm{CF}_{2}\right)-\delta(\mathrm{C}-\mathrm{C}-\mathrm{C})+\delta^{\prime}(\mathrm{C}-\mathrm{C}-\mathrm{C})\right)$, is very evident in the spectrum of Solef 1010 (Fig. 1) compared to the other spectra. This corresponds to a good stereoregularity of this sample, the proportion of perfect chains being $90.4 \%$, the best value for the samples studied in this work. The Solef 1010, like the Rhône-Poulenc films, presents a very typical farinfrared transmission profile in the region of $240 \mathrm{~cm}^{-1}$, which gives a general base line shape with a maximum transmission in this region. The two other samples present a rather straight base line in their far infrared spectra (Figs. 2 and 3). The spectrum of Kureha, KF 1000 (Fig. 2), presents a base line deflection in the region of $200 \mathrm{~cm}^{-1}$, corresponding to a very broad absorption in this region. Nevertheless the $215 \mathrm{~cm}^{-1}$ band $\left(\delta(\mathrm{C}-\mathrm{C}-\mathrm{C})+\delta^{\prime}(\mathrm{C}-\mathrm{C}-\mathrm{C})+r\left(\mathrm{CF}_{2}\right)\right)$, appears clearly on this continuous background.

After polarization (dashed line), we observe in all cases a strong decrease of the absorption bands characteristic of the $\alpha$ phase. For the samples KF 1000, Kynar 200 and Rhône-Poulenc, the absorption bands at $104-210$ and $288 \mathrm{~cm}^{-1}$ as well as the $54 \mathrm{~cm}^{-1}$ (libration of $\alpha$ lattice) disappear almost totally. The $350 \mathrm{~cm}^{-1}$ band $\left(t\left(\mathrm{CF}_{2}\right)+r\left(\mathrm{CF}_{2}\right)\right)$ and the $380 \mathrm{~cm}^{-1}$ band $\left(r\left(\mathrm{CF}_{2}\right)\right)$, remain present, but are weaker. In the spectrum of Solef 1010 (Fig. 1), the decrease of the $\alpha$ vibrations is comparatively less than in the other spectra. All of the $\alpha$ bands remain present although they are weak.

For all of the samples the presence of the polar

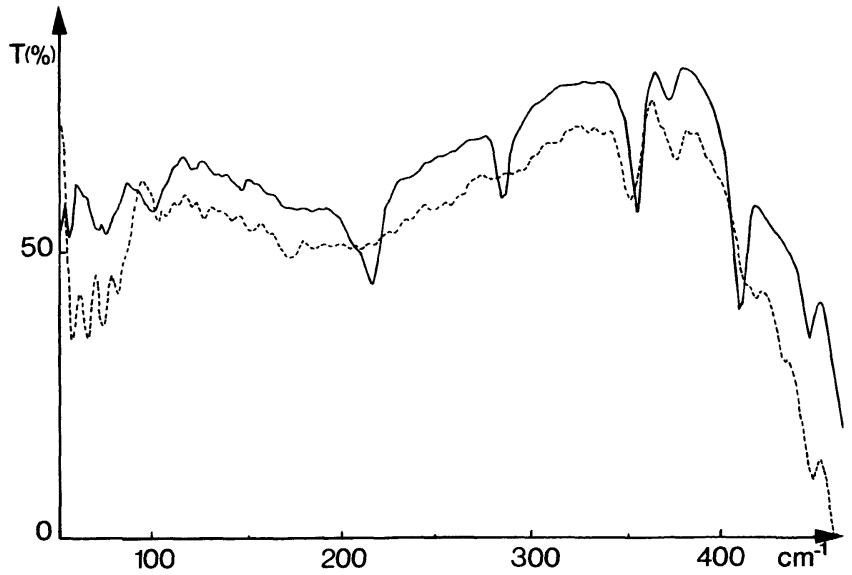

Fig. 2. - Far infrared spectra of KF 1000 in perpendicular polarized light. Continuous line : before polarization; dashed line : after polarization.

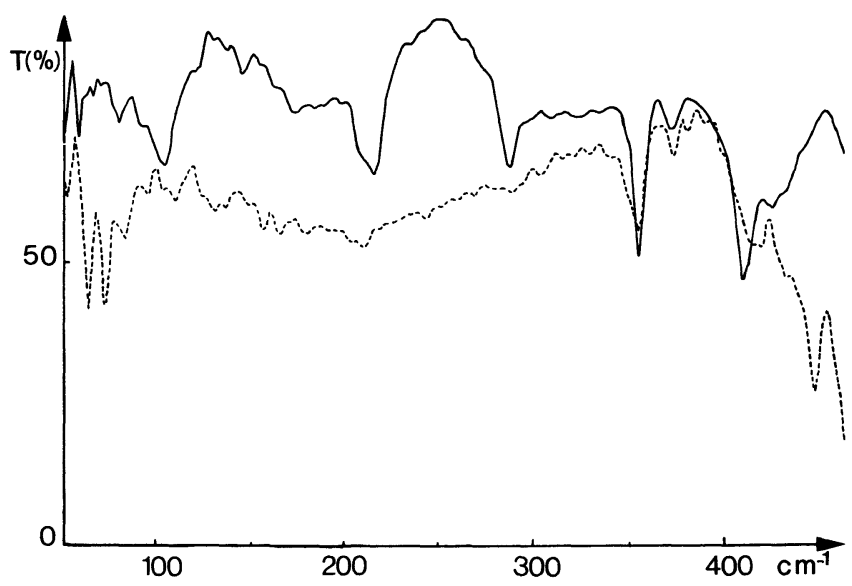

Fig. 3. - Far infrared spectra of Kynar 200 in perpendicular polarized light. Continuous line : before polarization; dashed line : after polarization.

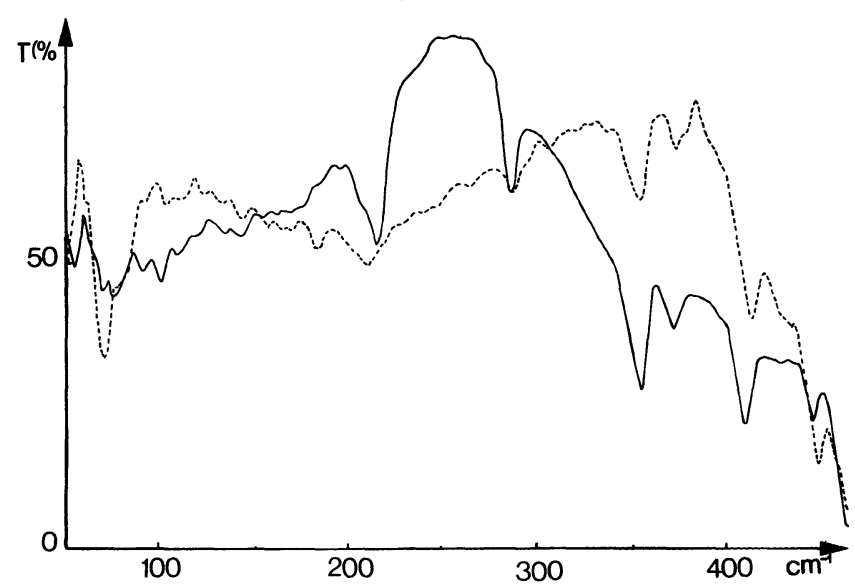

Fig. 4. - Far infrared spectra of Rhône-Poulenc in perpendicular polarized light. Continuous line : before polarization; dashed line : after polarization. 
phase $(\beta)$ characterized by the $70 \mathrm{~cm}^{-1}$ band (libration of the $\beta$ lattice mode) and the $444 \mathrm{~cm}^{-1}$ band $\left(r\left(\mathrm{CF}_{2}\right)+r\left(\mathrm{CH}_{2}\right)\right)$, is more accentuated, but the evaluation of this increase of the polar phase is easier and clearer in the mid-infrared region from the evaluation of the ratio $D 510(\beta) / D 530(\alpha) \mathrm{cm}^{-1}$, as indicated in the next paragraph.

We note (without definitive explanation) that the variations of the continuous back-ground of the spectra in the region $200 \mathrm{~cm}^{-1}$ appears clearly after polarization on all samples except in the case of Solef 1010. The spectral profile of the Rhône-Poulenc samples (Fig. 4) appears close to that of the Solvay spectra before polarization, with a maximum of transmission in the $250 \mathrm{~cm}^{-1}$ region, but after polarization, the profiles of the spectra look like the Kureha or Pennwalt sample spectra, with a very broad absorption band in the $180-200 \mathrm{~cm}^{-1}$ region.

The spectra of the four samples in the mid infrared region are presented on figures 5 to 8 . The assignment of all of the vibrational bands for the $\alpha$ and $\beta$ phases have been given previously by a number of authors [9-12]. Typically as in the far infrared region, all absorption bands of the $\alpha$ and $\beta$ crystalline forms are present in the four samples.

The general profile of the spectra before polarization also presents some differences in the different samples. In this region, the differences are primarily related to the amount of $\alpha$ and $\beta$ phase of each sample. For instance, the equal proportion of $\alpha$ and $\beta$ phases in Solef 1010 (Fig. 5) is clearly evident as compared to the other spectra, indicating a lower percentage

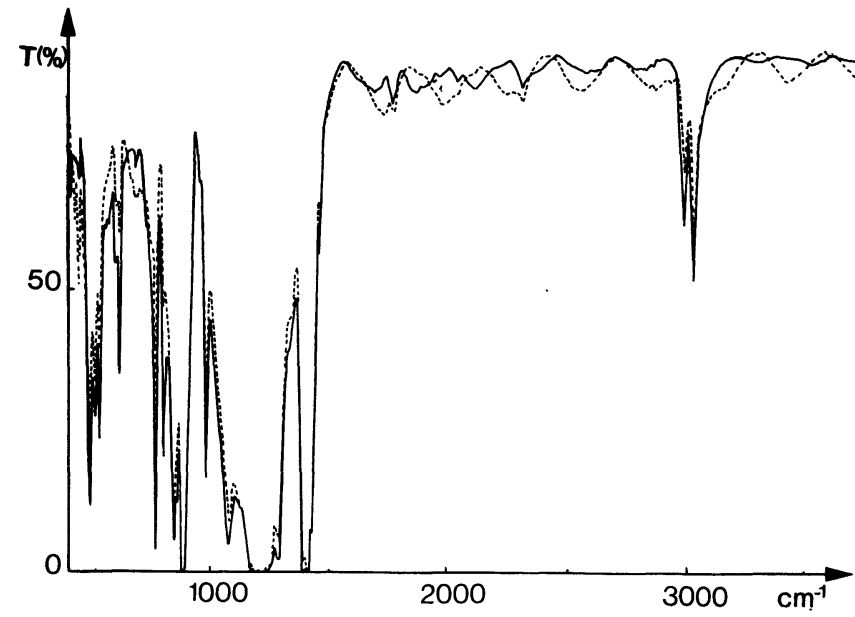

Fig. 5. - Mid infrared spectra of Solef 1010 in perpendicular polarized light. Continuous line : before polarization; dashed line : after polarization.

of the polar phase. The $\alpha$ absorption mode at $610 \mathrm{~cm}^{-1}$ $\left(\delta\left(\mathrm{CF}_{2}\right)-\delta^{\prime}(\mathrm{C}-\mathrm{C}-\mathrm{C})\right)$ is particularly sensitive to the amount of $\alpha$ phase present in the mixture.

After polarization of the samples, major differences appear in the spectra. The results are summarized on table II, showing the evolution of the $510 \mathrm{~cm}^{-1}$ band $\left(\delta\left(\mathrm{CF}_{2}\right)\right)$ for the $\beta$ phase and the $530 \mathrm{~cm}^{-1}$ band $\left(\delta\left(\mathrm{CF}_{2}\right)\right)$ for the $\alpha$ phase.

In table II, we have noted the ratios $D 510(\beta) /$ $D 530(\alpha)$ before and after polarization. This ratio has been used by several authors [6-12-13-14] to indicate

Table II. - Phase transition of polyvinylidene fluoride under polarizing field action $(E=1 \mathrm{MV} / \mathrm{cm})$.

\begin{tabular}{|c|c|c|c|c|c|c|c|}
\hline \multicolumn{8}{|c|}{ Phase transition of PVDF under field action $(1 \mathrm{MV} / \mathrm{cm})$} \\
\hline \multicolumn{2}{|l|}{ Origin } & \multirow{3}{*}{ 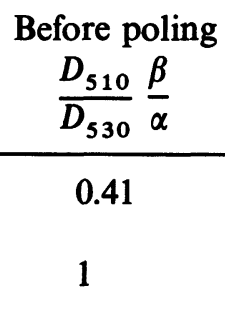 } & \multirow{3}{*}{$\begin{array}{c}\text { After poling } \\
\frac{D_{510}}{D_{530}} \frac{\beta}{\alpha} \\
1 \\
2\end{array}$} & \multirow{3}{*}{\begin{tabular}{|c}
$\begin{array}{c}\text { Decrease of } \alpha \\
D \text { before poling } \\
D \text { after poling }\end{array}(530)$ \\
1.8 \\
2
\end{tabular}} & \multirow{3}{*}{ 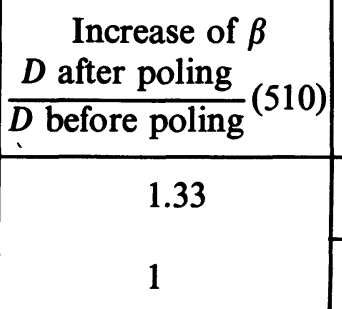 } & \multicolumn{2}{|c|}{$\begin{array}{c}\text { Piezoelectric } \\
\text { activity } \\
\text { pc/N }\end{array}$} \\
\hline $\begin{array}{c}\text { Solef } \\
\text { XION }=1010\end{array}$ & $\perp$ & & & & & $d_{31}$ & $d_{32}$ \\
\hline (Solvay) & $\mathscr{V}$ & & & & & 8 & 8 \\
\hline $\begin{array}{l}\text { KF } 1000 \\
\text { (Kureha) }\end{array}$ & $/ /$ & $\begin{array}{l}1.08 \\
0.307\end{array}$ & $\begin{array}{r}4.60 \\
20.6\end{array}$ & $\begin{array}{r}4.16 \\
28.66\end{array}$ & $\begin{array}{l}1.04 \\
2.23\end{array}$ & 9 & 5 \\
\hline $\begin{array}{l}\text { Kynar 200 } \\
\text { (KCF) } \\
\text { (Pennwalt) }\end{array}$ & $/$ & 0.09 & 1.2 & 2.06 & $\begin{array}{c}14.3 \\
2\end{array}$ & 17 & 0.2 \\
\hline $\begin{array}{l}\text { Rhône- } \\
\text { Poulenc }\end{array}$ & $\perp$ & $\begin{array}{l}1.2 \\
0.33\end{array}$ & 1.4 & $\begin{array}{l}5 \\
2.11\end{array}$ & 2.08 & 15 & 0.5 \\
\hline
\end{tabular}


the evolution of the polymer structure during the phase transition of PVDF. However this ratio alone does not give a very acurate indication of the phase transition process : it must be supplemented by the evaluation of the decrease in the $\alpha$ (D 530 before polarization/D 530 after polarization) and the corresponding increase of $\beta$ (D 510 after polarization/ $D 510$ before polarization) (Table II).

If we observe the evolution of the ratio $D 510 / D 530$, for all the various samples studied, we note a rather strong increase in this ratio from 0.3 to 20 for Kureha KF 1000, about two times for Solef 1010, four times for Rhône-Poulenc and about ten times for Kynar KCF 200. The fact that these values differ from one sample to the other, this does not necessarily indicate that the amount of $\beta$ phase varies accordingly. For example, the values shown do not suggest that the amount of $\beta$ phase increases more in the KF 1000 than in the Solef 1010. The second part of table II indicates that during the phase transition the major change is for all samples the strong decrease in the amount of $\alpha$ phase. For Solef 1010, the proportion of $\beta$ remains more or less constant before and after polarization but the amount of $\alpha$ decreases by about a factor two. For KF 1000, the increase in $\beta$ is also weak, during the polarization process, less than two time. However, the corresponding decrease in $\alpha$ is very great 4 to 20 times less after polarization. The Kynar KCF 200 is the only sample presenting an increase in the $\beta$ phase which is larger than the corresponding decrease in $\alpha$ as noted in perpendicular polarized light. For the Rhône-Poulenc films, as for Solef 1010 and KF 1000, the amount of $\beta$ phase remains more or less constant or increases slightly (two times maximum) with a corresponding decrease in $\alpha$, from 2 to 5 times the value before polarization.

Accordingly, following other authors, we can suppose that the crystalline phase generated during electrical polarization is dipolar [4], coming from a reorientation of the dipoles in the $\alpha$ crystalline phase. If this conclusion is correct for the KF 1000 or Rhône-Poulenc samples (where the increase in $\beta$ is slightly positive), for Solef 1010 it is difficult to detect a change of phase (nonpolar $\alpha$ to $\beta$ ). The proportion of $\beta$ appears to remain constant and a decrease in the nonpolar $\alpha$ crystalline part of the polymer is observed. For Kynar 200, the results in perpendicular polarized light show clearly an increase in the amount of $\beta$ which is more important than the corresponding decrease in $\alpha$. This part of the $\beta$ phase may be generated from the amorphous regions of the polymer; a mechanism which cannot be excluded in the other samples.

We have noted, as pointed out by other authors [15-17], the slight increase in the crystallinity of the polymers after polarizing as detected by X-ray diffraction or density measurements.

The influence of the structure of PVDF on the resulting piezoelectric activity after polarizing is

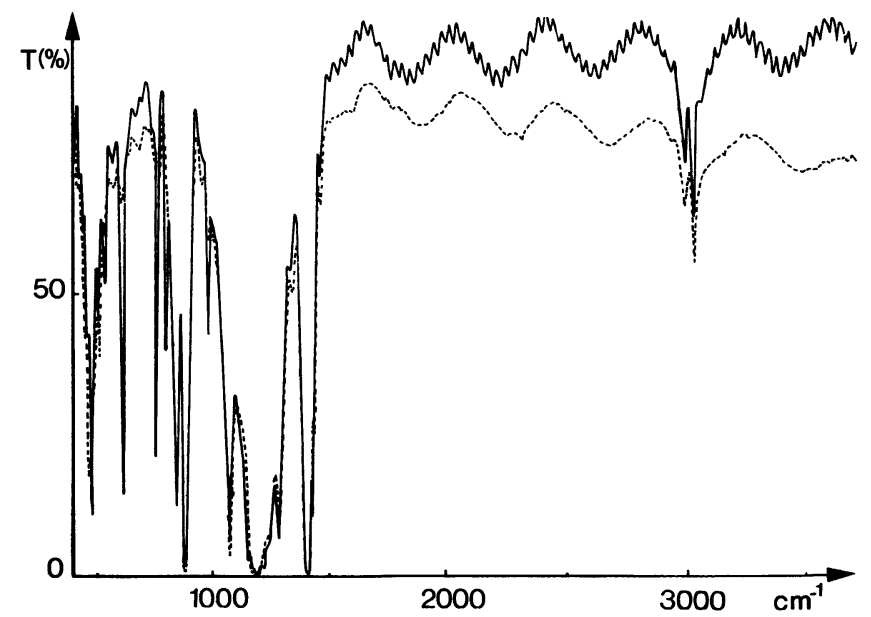

Fig. 6. - Mid infrared spectra of KF 1000 in perpendicular polarized light. Continuous line : before polarization; dashed line : after polarization.

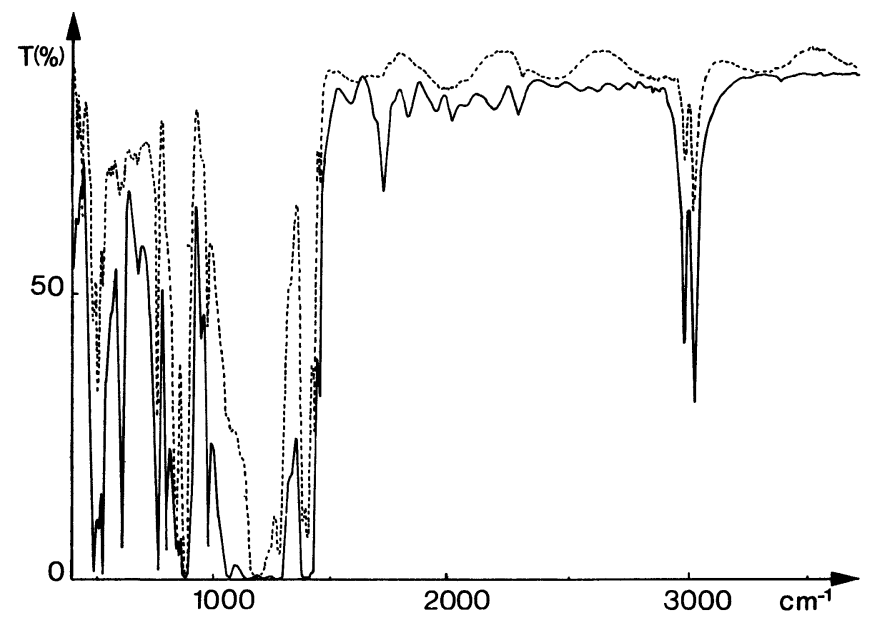

Fig. 7. - Mid infrared spectra of Kynar 200 in perpendicular polarized light. Continuous line : before polarization; dashed line : after polarization.

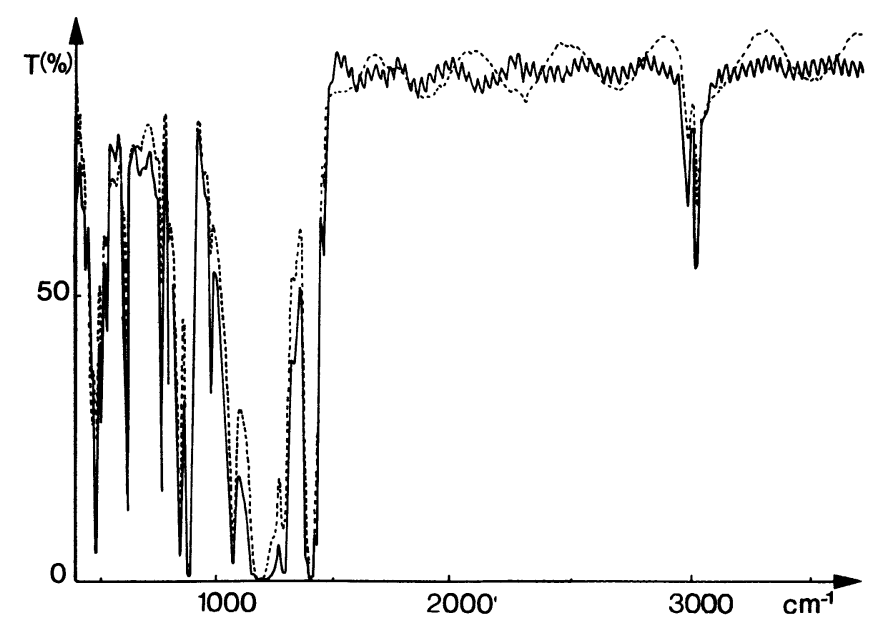

Fig. 8. - Mid infrared spectra of Rhône-Poulenc in perpendicular polarized light. Continuous line : before polarization; dashed line : after polarization. 
shown in table II. The samples which were stretched biaxially present a non-negligible $d_{32}$ coefficient, but it would seem that the samples presenting the largest increase in the $\beta$ phase during polarizing would also present a larger piezoelectric coefficient. It appears also that even if the amount of $\beta$ phase does not change during polarization, the samples with an initial large amount of $\beta$ phase before polarization present a very good piezoelectric activity after polarization.

\section{Conclusion.}

Under the same polarizing conditions, for a resulting similar piezoelectric activity, each sample appears to reach this result by different mechanisms : an initial low (9\%) proportion of $\beta$ (KCF 200) and a very important increase of this phase during polarization; or a large (50\%) initial proportion of $\beta$ (Solef 1010) without any particular change during polarization for two samples (KF 1000 and R.P.) a proportion of $23 \%$ of the $\beta$ phase and an increase in this phase of about two times during polarization. In all cases, a strong decrease in the $\alpha$ phase concentration is associated with the process of polarization.

\section{References}

[1] Lando, J. B., Olf, H. G., Peterlin, A., J. Polym. Sc. A 1, 4 (1966) 941.

[2] Southgate, P. D., Appl. Phys. Lett. 28, 5 (1976) 250.

[3] Davis, G. T., Mackinney, J. E., Broadhurst, M. G., Roth, S. C., J. Appl. Phys. 49 (1978) 4010, 4998.

[4] Das Gupta, D. K., Doughty, K., J. Phys. D Appl. Phys. 13 (1980) 95.

[5] Newman, B. H., Yoon, C. H., Pae, K. D., SheinBeIM, J. I., J. Appl. Phys. 50, 10 (1979) 6095.

[6] Geneves, G., Thesis Montpellier Univ. (1981).

[7] Nix, E. L., Holt, L., McGrath, J. C., Ferroelectrics 32 (1981) 103.

[8] Latour, M., Montaner, A., Galtier, M., Geneves, G., J. Polym. Sc. Polym. Phys. Ed. 19 (1981) 1121 .
[9] Kobayashi, M., Tashiro, R., TAdokoro, H., Macromolécules 3 (1975) 158.

[10] Enomoto, S., Kawai, Y., Sugita, M., J. Polym. Sc. A 2 (1968) 861.

[11] LATOuR, M., Intern. Symp. on Electrets and Dielectrics, Rio de Janeiro (1977) p. 239-254.

[12] Latour, M., Polym. 18, 3 (1977) 278.

[13] Osaki, S., KotaKa, T., Ferroelectrics 32 (1981) 1.

[14] Osaki, S., Ishida, Y., J. Polym. Sc. Polym. Phys. Ed. 13 (1976) 1079.

[15] LAtour, M., J. Electrost. 2 (1976) 241.

[16] Latour, M., Galigne, J. L., Abbo-Dorra, H., J. Polym. Sc. Poly. Phys. Ed. 22 (1984) 345-356. 